\title{
OPTIMAL BOUNDS FOR THE SÁNDOR MEAN IN TERMS OF THE COMBINATION OF GEOMETRIC AND ARITHMETIC MEANS
}

\section{Wei-Mao Qian, Chun-Lin Ma And Hui-Zuo Xu*}

Abstract. In this paper, we prove that $\lambda=1 / 2-\sqrt{1-e^{-2 / p}} / 2$ and $\mu=1 / 2-\sqrt{6 p} /(6 p)$ are the best possible parameters on the interval $(0,1 / 2)$ such that the double inequalities

$$
\begin{gathered}
G^{p}[\lambda a+(1-\lambda) b, \lambda b+(1-\lambda) a] A^{1-p}(a, b)<X(a, b) \\
<G^{p}[\mu a+(1-\mu) b, \mu b+(1-\mu) a] A^{1-p}(a, b)
\end{gathered}
$$

hold for all $p \in[1, \infty)$ and $a, b>0$ with $a \neq b$, where $G(a, b)$ is the geometric mean, $A(a, b)$ is the arithmetic mean, and $X(a, b)$ is the Sándor mean.

Mathematics subject classification (2020): 26E60.

Keywords and phrases: Sándor mean, geometric mean, arithmetic mean, inequality.

\section{REFERENCES}

[1] G. D. Anderson and M. K. Vamanamurthy and M. Vuorinen, Conformal Invariants, Inequalities, and Quasiconformal Maps, John Wiley \& Sons, New York, 1997.

[2] Y.-M. Chu AND M.-K. WANG AND Y.-F. QIU AND X.-Y. MA, Sharp two parameter bounds for the logarithmic mean and the arithmetic-geometric mean of Gauss, J. Math. Inequal. 7, 3 (2013), 349-355.

[3] Y.-M. Chu And ZH.-H. YAng AND L.-M. Wu, Sharp power mean bounds for Sándor mean, Abstr. Appl. Anal., Article ID 172867, (2015), 1-9.

[4] E. Neuman And J. SÁndor, On the Schwab-Borchardt Mean, Math. Pannon. 14, 2 (2003), 253 266.

[5] W.-M. QIAN AND Y.-M. ChU AND X.-H. ZHANG, Sharp bounds for Sándor mean in terms of arithmetic, geometric and harmonic means, J. Inequal. Appl. 2015, 221 (2015), 1-13.

[6] J. SÁNDOR, Two sharp inequalities for trigonometric and hyperbolic functions, Math. Inequal. Appl. 15, 2 (2012), 409-413.

[7] J. SÁndor, On two new means of two variables, Notes Number Theory Discrete Math 20, 1 (2014), $1-9$.

[8] S.-S. Zhou, W.-M. Qian, Y.-M. Chu, X.-H. Zhang, Sharp power-type Heronian mean bounds for the Sándor and Yang means, J. Inequal. Appl. 2015, (2015), 1-10. 